\title{
Humanitarian Logistics - An Exposition of the Challenges to Rapid Response in Disaster Relief Operations in Ghana
}

\author{
Article by Japhet Baidoo \\ Doctor of Philosophy (PhD) in Management, Texila American University, Georgetown, Guyana \\ Email: japhetbaidoo@yahoo.com
}

\begin{abstract}
Response, coordination and collaboration of among humanitarian organisations became more challenging in the use of local logistics and human resources in humanitarian relief operations. This proposal provides a plan for examining humanitarian logistics with specific emphasis on the challenges to rapid response in disaster relief operations in Ghana. The proposal identified the research problem and out of the research problem, it developed research objectives and research questions. The research framework is also outlined to provide a structural outlook of the thesis. The framework for the literature review was presented and this dwelt on four main parts namely theoretical review, empirical review, conceptual review and deduction from the literature. The method to be employed and the procedure and tools for data collection were also provided and this also include the method of data analysis. The time frame, resources required and budget for the conduct of the research were presented in this proposal. The expected output of the thesis was stated and the societal and scientific relevance of the study were also given. The ethical issues associated with the conduct of this study were stated and the procedure for observing and addressing the ethical considerations were also presented.
\end{abstract}

\section{Introduction}

This thesis deals with humanitarian logistics with specific emphasis on the challenges to rapid response in disaster relief operations in Ghana. Over the last two decades, humanitarian logistics has received tremendous attention in both field of human endeavor and scholarly research. The evolving trend of humanitarian logistics was triggered by series of disasters that erupted in the world and their attendant problems. For instance, the 2004 Indian Ocean Tsunami disaster generated unprecedented global outcries regarding poor logistics management. This disaster and the criticisms of its management provided a turning point for humanitarian logistics (Kovacs and Spens, 2011).

In 2006, came actual breakthrough for humanitarian logistics management with far improved performance and responsiveness to disaster situations. In effect, coordination and collaboration of among humanitarian organizations became more challenging in the use of local logistics and human resources in humanitarian relief operations (Overstreet at al., 2011). Unfortunately, disasters upon disasters keep striking and disaster reliefs have also become increasingly demanding making humanitarian logistics globally more challenging, given the complexities and uncertainties involved (OCHA, 2010). Ghana is no exception in this regard, as in the past two decades the country has experienced series of disasters. Natural disasters in Ghana can be categorized into floods, epidemics, wildfires, earthquakes and droughts. However, in recent times, the major disasters that occurred in Ghana were industrial and wildfires, floods and epidemics (Aboahye, Dari and Koomson, 2013; Amposah, 2004). For example, devastating flood disasters that affected Ghana in the last decade occurred in 2003, 2007, 2009, 2010 and 2015. The 2010 and 2015 were the most devastating in recent memory in terms of morbidity, mortality, destructions of physical infrastructures, economic and social adverse effects that came with those disasters. With respect to epidemics, cholera is found to be entrenched disaster posing great concern in Ghana. For example, from 1970 to 2003, four major cholera outbreaks occurred and thus, 1970 and 1972 recorded 16,406 cases of cholera, between 1980 and 1985, 27,489 cases were recorded, and between 1989 and 1992, 5,973 cholera cases were recorded while in 2003, 25,494 cases were recorded (Osei, 2010). The most recent cholera 
DOI: $10.21522 /$ TIJMG.2015.03.02.Art024

ISSN: $2520-310 \mathrm{X}$

outbreak was in 2014 which occurred in 130 districts out of the 216 districts in Ghana recording 28,975 cases with a death toll of 243. This outbreak protracted and had a spill over to 2015 recording 591 cases with 5 deaths as at May, 2015.The cholera epidemic is found to be fostered and triggered by heavy rains and floods across Ghana (WHO, 2015). These examples of disasters cannot go without the mention of fire disaster which is found to be an annual catastrophic occurrence and its prevalence is very high. Fire disasters in Ghana is said to cost the nation in terms of value of properties destroyed to the tune of US\$16million annually (Norman et al., 2015).

All the above examples of disasters in Ghana are indication of the fact the need for effective response to disasters in Ghana cannot be over-emphasized. This has call has been echoed by Van Wassenhove (2006) that "a successful response to a disaster is not improvised. The better one is prepared the more effective the response" (Van Wassenhove, 2006:480). However, in most cases, the response of the humanitarian organizations in Ghana to disasters is fraught with challenging constraints making rapid response ineffective (Buatsi, 2007).

It is against the above backdrop that this thesis is being conducted to provide an in-depth exposition of the challenges to rapid response in disaster relief operations in Ghana.

\section{Identification of research problem}

Natural disasters are catastrophes that are beyond the control of humans. However, the effects of natural disasters can be reduced through rapid response and effective post-disaster management strategies. Despite this, humanitarian organizations are faced with bottlenecks and disruptions in terms of receipt, warehousing, transportation, tracking, delivering of relief items and post-disaster strategies making relief efforts inefficient and ineffective (Christopher and Tatham, 2011).

In recent times, the most alarming and devastating disasters in Ghana are floods, fires and epidemic. These disasters have claimed many lives and cost the nation hundred million dollars annually. Seriously, response to disasters and managing of disasters augmented by disaster relief organizations in Ghana present operational constraints to regional and national disaster response and management capacity. For example, on several occasions, the response to floods and fire disasters by the disaster relief organizations such as the National Disaster Management Organization (NADMO), the Ghana National Fire Service among other organization was ineffectively executed. In most disasters there were experiences of delays and flaws in disaster response execution leading to increased casualties and worsened conditions of disaster victims. Furthermore, coordination of logistics in humanitarian operations in Ghana especially during emergencies is very daunting due to the distinct nature of the disaster and emergencies as well as the high involvement of stakeholder organizations (Aboagye, Dari and Koomson, 2013; Allotey, Arku and Amponsah, 2010). From the studies one is unclear as to why the delays, effective coordination of logistics, flaws in disaster response execution among other pertinent and mind-boggling issues affecting disaster relief operations in Ghana. There is therefore the need examine the challenges to rapid response in disaster relief operations in Ghana.

Moreover, an area that prompts investigations into the challenges to rapid response in disaster relief operations in Ghana is the gaps that exists in the literature. It has been found that there is scanty knowledge of humanitarian logistics among logistics practitioners and academics necessitating the development of adequate competencies and empirical studies on humanitarian logistics (Kovacs and Spends, 2007; Van Wassenhove, 2006). Careful search of current literature indicates that there have been several empirical studies in other part of the world on post-disaster response as well as reconstruction (Vale and Companella, 2005; Burby and Deyle, 2000; Berke et al, 1993). However, in the Ghanaian context very few studies have been conducted on disasters management (Aboagye, Dari and Koomson, 2013), earthquake disaster (Allotey, Arku and Amponsah, 2010) and flood disaster (Osei, 2010). In effect, humanitarian logistics and challenges in disaster response in Ghana have received little scholarly attention despite the growing occurrence of disasters in Ghana and the magnitude of the effects that the disasters have on Ghana as a whole. There is indeed timely attempt to provide an in-depth and relevant knowledge on how to improve 
coordination and speed in responding to disasters in Ghana. The key to improved ability, capability and speed in humanitarian relief efforts is to examine the challenges confronting humanitarian logisticians or disaster relief organizations and provide appropriate antidotes in addressing them.

\section{Research objectives}

\section{General objective}

The main aim of this thesis is to examine humanitarian logistics and the challenges to rapid response in disaster relief operations in Ghana.

\section{Specific objectives}

The specific objectives of the study are as follows:

i. To study the trend of disasters and the extent of the casualties of the disasters for the past five years.

ii. To ascertain the features of humanitarian logistics in Ghana.

iii. To assess the roles played by humanitarian organizations in Ghana.

iv. To examine the barriers/constraints to effective response in disaster relief operations.

v. To explore and propose strategies of ensuring rapid response in disaster relief operations.

\section{Research questions}

The thesis seeks to address the following research questions:

i. What is the trend of disasters in Ghana for the past five years and to what extent have the casualties affected Ghana?

ii. What features of are peculiar to humanitarian logistics in Ghana?

iii. What roles are played by humanitarian organizations in Ghana?

iv. What are the barriers/constraints to effective response in disaster relief operations?

v. How can rapid response in disaster relief operations be achieved?

\section{Research framework}

The thesis will be structured in six main chapters as follows:

\section{Chapter one}

This chapter will be the introduction which provides background to study, problem identification and explanation, research objectives, research questions, significance of the study, scope and limitations of the study and organization of the study.

\section{Chapter two}

Chapter two will review scholarly articles, researches, books and other relevant publications related to the thesis. The literature reviews will be designed in providing an overview of sources explored and other materials that are useful to the study and the justifications for their use. The chapter will focus on theoretical reviews, empirical reviews and conceptual framework.

\section{Chapter three}

The chapter three of the thesis will focus on research methodology and this will cover, the research strategy, research design, population, sampling and sampling size, data collection instruments, data collection procedure, pre-testing, validity and reliability and data analysis technique.

\section{Chapter four}

Chapter four will be results and discussions and it will also present the results obtained from the field. The results will be analyses and the findings obtained will be discussed in line with the research questions. 
DOI: $10.21522 /$ TIJMG.2015.03.02.Art024

ISSN: $2520-310 \mathrm{X}$

\section{Chapter five}

This chapter will be conclusion and recommendations. It will also contain summary of the research findings and as well as suggestions for further studies.

\section{Literature review}

The literature review will dwell on four main parts namely theoretical review, empirical review, conceptual review and deduction from the literature. This sections are explained below:

\section{Theoretical review}

Though humanitarian logistics is said to be gaining prominence in developing countries, the application of its theories have not had the needed attention in developing countries. Therefore, the theoretical framework in this thesis will dwell on time-tested theories which embody the findings of several investigations on humanitarian logistics. It will provide a general representation of relationships between things in a given phenomenon.

\section{Empirical review}

This section of the literature review will present the findings of other empirical studies that are related to the subject matter. The findings will be critiqued based the strengths and weakness of the methods and analyses used in arriving at those findings.

\section{Conceptual framework}

The conceptual framework is the researcher's idea on how the research problem will have to be explored. This will be based on the theoretical and empirical reviews, which lies on a much broader scale of resolution. The conceptual framework embodies the specific direction by which the thesis will have to be undertaken. The conceptual framework will describe the relationship between specific variables to be identified in the study.

\section{Deductions from the literature}

Based on literature reviews, deductions will be made to highlight on the research gaps. This means that the literature review will help to identify the gaps in previous studies and how this study intends to fill the gaps.

\section{Research methodology}

This section will provide explanations on the methods to be employed for the study. This includes the research approach, design, sampling, instruments for data collection, data collection procedure, data analysis method.

\section{Research approach}

The study adopted both qualitative and quantitative research methods. The decision to combine quantitative and qualitative methods in this study can also be justified on the grounds that it made it possible for the researcher to explore the research questions from different perspectives which lead to broader understanding of issues relating to topic (Bryman, 2004).

\section{Research design}

According to Burns and Grove (2003), research design is a blueprint for conducting a study with maximum control over factors that may interfere with the validity of the findings. Parahoo (1997) also defines research design as a plan that describes how, when and where data are to be collected and analyses. In this view, descriptive research design was appropriate for this study.

The perspective of the research was based on Ghana and it involved the major disaster relief organizations in Ghana. The study employed descriptive research design that focused on in-depth 
description of humanitarian logistics, disaster relief operations in Ghana and the associated challenges in disaster response. The main aim of this descriptive research is to provide an accurate and valid representation of (encapsulation) the factors or variables that pertain / are relevant to the research questions, so as to present a clear (descriptive) picture of the challenges in rapid response in disaster relief operations in Ghana.

\section{Population}

Sekaran (1991) wrote that sampling is the process of selecting a sufficient number of elements from a population so that by studying the sample and understanding the properties or characteristics of the sample, researchers would be able to generalize the properties of the sample to the population. Saunders et al. (1997) indicated that the size of the sample and the way in which it is selected definitely has implication for the confidence level and an extent to which generalization can be made. The criteria for inclusion in this study were based on the fact that the organization must be involved in disaster relief operations in Ghana. The major 12 disaster relief organization in Ghana constituted the target population for this study. Therefore, one official (being the mouthpiece) representing each respective organization was involved in the study. The major organizations targeted were (1) the United Nations Humanitarian Response Depot (UNHRD); (2) World Vision - Ghana, (3) Adventist Development Relief Agency (ADRA); (4) CARE International; (5) the National Disaster Management Organization (NADMO): (6) the Ghana Armed Forces; (7) Ghana Police Service; (8) Ghana National Fire Service; (9) National Ambulance Service (NAS); (10) St. John's Ambulance Service (SAS); (11) United Nations High Commission for refugees and (12) World Vision Ghana.

\section{Sampling technique and procedure}

Sampling is the process of selecting a group of people, events or behavior with which to conduct a study (Burns and Grove, 2003). This study will employ stratified sampling techniques in for selecting for the study. Stratified sampling technique is where the elements in the population are first divided into groups called strata. The basis for choosing this sampling technique is due to the heterogeneous nature of the target population. In order to do this, the population was put into two strata (subgroups). The total membership of each group (each disaster relief organization) forms the sample frame for the study and the total number of the members will then be expressed in percentage terms to obtain the sample size.

\section{Research instruments and data collection}

\section{(i) Questionnaire}

According to Yin (2004), questionnaires are the most appropriate method for case study. For the purpose of this study questionnaires were used because it helped to collect the relevant data from the large number of respondents in various selected locations. It also ensured that standardized data were collected from identical questions without the need to have face to face interaction. Apart from these, it saves time and resources. Also, the questionnaire enabled the researcher to collect relevant data in respect of the same variables for everyone in the sample selected (Zahari, 2007). This makes the questionnaire an indispensable tool in gathering primary data about people, their behaviour, attitudes, opinions and awareness of specific issues. Therefore, the study will design questionnaire to seek the views of the respondents based on the research questions

\section{(ii) Interviews}

Interview guide consisting of open-ended questions will be designed seek the views of key representatives of the disaster relief organizations. The interviewees will be key in the respective organization and they should be directly involved in disaster relief operations in Ghana. In ensuring that the interviewees freely express their views and provide relevant data for this study, they will be assured of anonymity and that their personality would not be revealed. For this reason, the study will use acronyms in 
DOI: $10.21522 /$ TIJMG.2015.03.02.Art024

ISSN: $2520-310 \mathrm{X}$

referring to the interviewees. Their profiles will be attached to the study as an appendix. Although the main weakness of interview is that it is expensive in terms of time and cost, it also contributes significantly in obtaining adequate and relevant data for the study. Also it ensures flexibility and adaptability in the faceto-face encounter. It allows for follow-up questions to be made on the spot (Sounder et al., 2003).

\section{Data analysis method}

The study will use the 5-Likert scale in analyzing the data to be obtained from the questionnaire. The 5Likert scale will be made up of $1=$ strongly disagree; $2=$ Disagree; $3=$ Indifferent; $4=$ Agree and $5=$ strongly agree.

Based on the responses to the questionnaire using the above scale, the following Weighted Mean Average formula will be used to compute the overall results for the various variables to address the research questions.

$$
W M A=\frac{\sum W}{A N}=\frac{5 n_{5}+4 n_{4}+3 n_{3}+2 n_{2}+1 n_{1}}{5 N} \ldots \ldots \ldots \ldots \ldots \ldots \ldots \text { eq. } 1
$$

The formula above is explained below:

WMA = Weighted Mean Average

A $=$ Highest weight (in this case 5)

$\mathrm{N}=$ Sample Size

$\mathrm{n}^{1}=$ Number of responses to "Strongly Disagree"

$\mathrm{n}^{2}=$ Number of responses to "Disagree"

$\mathrm{n}^{3}=$ Number of responses to "Indifferent"

$\mathrm{n}^{4}=$ Number of responses to "Agree"

$\mathrm{n}^{5}=$ Number of responses to "Strongly Agree"

The result from the computations using the above formula will then be compared with the Vagias (2006) Means Range values to obtain the appropriate interpretation to the specific variable in the questionnaire.

The results obtained from the interviews will analysis using thematic analysis framework. In this regard, the study will identify the main themes running through the results obtained. This means that the topical issues that are found common in the all the results will be categorized and analyses. This method of analysis is in consistent with Wetherill and Potter (1988) Interpretative Repertoire Method of analyzing interviews.

\section{Time schedule and resource requirement}

The thesis is scheduled to take 8 months to complete. This means that by $15^{\text {th }}$ November, 2016 , the draft copy of the thesis will be ready for submission. This is budgeted that GHф8,650.00 will be used to cover the research expenses. The table below illustrates the time, resource schedule and budget for the entire research processes. 
Table 1. Time, resource and budget schedule

\begin{tabular}{|c|c|c|c|c|}
\hline No. & Main Activity & $\begin{array}{l}\text { Anticipated } \\
\text { Start Time }\end{array}$ & $\begin{array}{l}\text { Anticipated } \\
\text { Completion Time }\end{array}$ & $\begin{array}{l}\text { Budged Cost of } \\
\text { stationery and } \\
\text { printing (GHC) }\end{array}$ \\
\hline 1 & Research Proposal & & $5^{\text {th }}$ April, 2016 & 100.00 \\
\hline 2 & Introduction (Chapter One) & $10^{\text {th }}$ April, 2016 & $15^{\text {th }}$ April, 2016 & 150.00 \\
\hline 3 & $\begin{array}{l}\text { Literature Review (Chapter } \\
\text { Two) }\end{array}$ & $25^{\text {th }}$ May, 2016 & $10^{\text {th }}$ May, 2016 & 300.00 \\
\hline 4 & $\begin{array}{l}\text { Methodology (Chapter } \\
\text { Three) }\end{array}$ & $15^{\text {th }}$ May, 2016 & $20^{\text {th }}$ May, 2016 & 50.00 \\
\hline 5 & $\begin{array}{l}\text { Data Collection - } \\
\text { Questionnaire }\end{array}$ & $25^{\text {th }}$ May, 2016 & $15^{\text {th }}$ June, 2016 & $1,000.00$ \\
\hline 6 & Data Collection - Interviews & $20^{\text {th }}$ June, 2016 & $5^{\text {th }}$ July, 2016 & 500.00 \\
\hline 7 & Data Collection - Statistical & $10^{\text {th }}$ July, 2016 & $15^{\text {th }}$ July, 2016 & 200.00 \\
\hline 8 & $\begin{array}{l}\text { Data Coding, collation and } \\
\text { entry }\end{array}$ & $20^{\text {th }}$ July, 2016 & $15^{\text {th }}$ Aug. 2016 & 250.00 \\
\hline 9 & $\begin{array}{l}\text { Data Analysis, presentation } \\
\text { and Discussion (Chapter } \\
\text { Four) }\end{array}$ & $15^{\text {th }}$ Aug. 2016 & $25^{\text {th }}$ Sept. 216 & 300.00 \\
\hline 10 & $\begin{array}{l}\text { Conclusion and } \\
\text { Recommendations (Chapter } \\
\text { Five) }\end{array}$ & $1^{\text {st }}$ Oct. 2016 & $15^{\text {th }}$ Oct. 2016 & 150.00 \\
\hline 11 & Compilation and editing & $20^{\text {th }}$ Oct. 2016 & $10^{\text {th }}$ Nov. 2016 & 250.00 \\
\hline 12 & Submission of Draft Report & & $15^{\text {th }}$ Nov. 2016 & \\
\hline \multicolumn{4}{|c|}{ Sub-Total } & $3,250.00$ \\
\hline \multicolumn{4}{|c|}{ Computer Laptop } & $2,500.00$ \\
\hline \multicolumn{4}{|c|}{ HP Printer } & 500.00 \\
\hline \multicolumn{4}{|c|}{ Internet Package } & 400.00 \\
\hline \multicolumn{4}{|c|}{ Research Assistant } & $2,000.00$ \\
\hline \multicolumn{4}{|c|}{ Grand Total } & $8,650.00$ \\
\hline
\end{tabular}

\section{Expected output}

It is expected that the output of this thesis will provide new knowledge in the area of humanitarian logistics and disaster relief operation in Ghana. Finally, the thesis will be published in one of the international publishing journals.

\section{Societal and scientific relevance}

This thesis is conducted to adequately improve speed in responding to disasters and victims of disasters in ensuring that there is reduced morbidity and mortality. By so doing the thesis will raise awareness of potential constraints affecting rapid response to disasters and disaster victims. It is also important to state that humanitarian logistics have much to offer the business world taking cognizance of the fact that, disasters affect businesses as well. Therefore, businesses could learn more from this study about vulnerability assessment, preparation and response to disasters. In the humanitarian world, logistics was long considered a back-office function. The growing attention of donors, academia and the general public has lately begun to change this underestimation of the logistics function.

The significance of this study is such that humanitarian logistics as a field is new and has not yet received the much needed academic attention as compared to other fields of study. Therefore, the researcher believes that more research is needed in different areas of humanitarian logistics, hence the need for this study to be 
DOI: $10.21522 /$ TIJMG.2015.03.02.Art024

ISSN: $2520-310 \mathrm{X}$

conducted. This study will provide systematic knowledge and understanding of management of dynamic and complex crises, the challenges to effective and efficient humanitarian logistical services delivery in Ghana and how to address these challenges so as to save more lives and enhance the quality of life of those affected.

\section{Ethical considerations}

Accessibility to data from some security outfit will not that easy, especially the Ghana Armed Forces. Due to security policy and information classification of the Ghana Armed Forces, certain procedural practices will need to be adhered. In order to avoid reluctance in divulging confidential data, official letter of permission will be sent for approval for access to the organizations and accessibility to data. The researcher will seek audience with the appropriate authority within the organizations through official appointments at which the researcher will explain the essence of the study to the participant organizations. The questionnaires and interview questions will be approved by the research supervisor before it will be carried out. The researcher will adhere to all ethical standards throughout the data collection processes. Participants will not be made to disclose their personal identity and will be assured that information provided by them will be treated strictly confidential and purely for academic purpose only.

\section{References}

[1].Aboagye, D., Dari, T. and Koomson, J. (2013) Risk Perception and Disaster Management in the Savannah Region of Ghana, International Journal of Humanities and Social Science Vol. 3 No. 3; pg. 1.

[2].Allotey, N. K., Arku, G. and Amponsah, P. E. (2010) Earthquake-disaster preparedness: The Case of Accra, International Journal of Disaster Resilience in the Built Environment, Emerald Group Publishing Limited, Vol. 1 No. 2, 2010, pp. 140-156. Accessed on $1^{\text {st }}$ April, 2016, available at: www.emeraldinsight.com/1759-5908.html

[3].Amponsah, P.K. (2004). Seismic activity in Ghana: Past, present and future. Annals of Geophysics, 47(2/3), 539543.

[4].Buatsi, S.N. (2007), "Humanitarian logistics: context and challenges in Ghana and Africa", International Conference on humanitarian logistics in Ghana.

[5].Norman, I.D., Awiah, B.M., Aikins, M. K. and Binka, F. N. (2015). Review of Catastrophic Fires and Risk Communication, Ghana, Advances in Applied Sociology, 2015, 5, 167-177. Accessed online on $2^{\text {nd }}$ April, 2016 at: http://www.scirp.org/journal/aasoci, http://dx.doi.org/10.4236/aasoci.2015.55016

[6].Osei, F. B. (2010), Spatial Statistics of Epidemic Data: The Case of Cholera Epidemiology in Ghana, PhD Thesis, University of Twente, Enschede, Netherlands.

[7].UNDP (2012), Community Resilience through Early Warning (CREW) to Disasters Project: Local Project Appraisal Report on Ghana, UNDP Ghana Office, Accra.

[8].Van Wassenhove, L.N. (2006), "Humanitarian aid logistics: supply chain management in high gear", Journal of the Operational Research Society, Vol. 57 No. 5, pp. 475-89.

[9].WHO (2015) Situation Report on Cholera Outbreak in Ghana as of 24 May 2015 (Week 21), Country Office Accra, Ghana. 